Didáctica. Lengua y literatura

ISSN: $1130-0531$

http://dx.doi.org/10.5209/DIDA.57139

\title{
La literatura, el niño y el adulto: por una didáctica de la extrañeza
}

\author{
Jesús Montiel López ${ }^{1}$
}

Recibido: 11 de noviembre de 2016 / Aceptado: 16 de mayo de 2017

Resumen. El interés que sentimos hacia la literatura cuando somos niños va debilitándose con el paso del tiempo. Entre el niño y la literatura, durante los primeros años de Primaria, suele producirse un alejamiento que concluye en el desencanto. El presente artículo, partiendo de esta ruptura, reflexiona sobre el niño y su creatividad desbordante, tan parecida a la del artista, y propone el abordaje del texto literario como un ser vivo y no como un objeto analizable para lograr una continuidad con la etapa infantil, donde el libro y el juego no están reñidos. Asimismo, se reivindica la literatura como una herramienta cognitiva capaz de aprehender la realidad en una época donde, cada día más, las Humanidades y el arte son barridos por la lógica del mercado.

Palabras clave: Literatura; Infancia; Creatividad; Lectura; Didáctica.

\section{[en] Literature, Child and Adult: Towards a didactics of astonishment}

\begin{abstract}
The attraction that we feel towards literature in our childhood gets weaker as time goes by. In the first years of elementary school, a distance between children and literature usually appears leading them into disappointment. From that fact, in this paper we reflect on children and their boundless creativity so similar to that one in the artist. We propose to approach to the literary text as we move closer to a living being and not as to an analysable object. In this way, we will get a certain continuity from the childish stage, where book and game are not at odds. Furthermore, we claim the utility of literature as a cognitive tool able to seize reality in a period where humanities and art are more and more swept by the logic of market.
\end{abstract}

Keywords:Literature; Children; Creativity; Reading; Teaching.

\section{[fr] Littérature, l'enfant et l'adulte : Pour une didactique de l'étonnement}

Résumé. L'intérêt que nous expérimentons vers la littérature pendant notre enfance s'affaiblit de plus en plus avec le cours du temps. Durant les premières années de l'école primaire, un éloignement entre les enfants et la littérature arrive qui aboutit dans le désenchantement. Dans cet article, nous réfléchissons, à partir de cette donnée, sur l'enfant et sa créativité débordante, si semblable à celle de l'artiste. Nous proposons l'approche à l'œuvre littéraire comme si elle serait un être vivant, et non un object d'analyse. De cette façon, nous obtiendrons une certaine continuité avec l'étape infantile, où le livre et le jeux ne sont pas brouillés. En plus, on se revindique la littérature comme un outil cognitif capable de nous faire capter la réalité dans une époque où les humanités et l'art sont de plus en plus balayés par la logique du marché.

Mots-clé: Littérature; enfants; créativité; lecture; enseignement.

Departamento de Ciencias Sociales

Universidad de Granada

jesus@eulainmaculada.es 
Sumario: 1. Punto de partida: algo ha sucedido. 2. El poeta y el niño. 3. La ruptura. 4. Invertir la situación: por una didáctica de la extrañeza.5. Conclusiones. 6. Bibliografía.

Cómo citar: Montiel López, J. (2017). La literatura, el niño y el adulto: por una didáctica de la extrañeza Didáctica. Lengua y literatura, 29, 2017, 207-219.

\section{Punto de partida: algo ha sucedido}

Al niño no le incomoda el cuento que escucha en el ámbito familiar. La rima del poema o un espectáculo con títeres, en el aula infantil, son actividades que lo estimulan y lo conducen a la investigación de su entorno y de sí mismo. Quiero decir que la literatura y la primera infancia se llevan bien; pero en el caso del adulto es diferente: mis alumnos, en la universidad, no solo no disfrutan con la literatura, sino que la encuentran tediosa y aburrida. La literatura es para ellos propiedad de unos tipos aislados, algo desapacible. Mucho más si reparo en los conocidos que me rodean a diario, para quienes un libro es algo muy lejano a la interacción o el gozo que proporciona un descubrimiento.

Algo ha sucedido entre el niño y el adulto; pero ¿cuándo y cómo? ¿Podemos conocer alguno de sus desencadenantes?

El presente artículo pretende ser una reflexión a propósito de esta ruptura que percibo en mi triple relación con la literatura: como padre, como profesor y también como poeta ${ }^{2}$. El trabajo, además, nace de un deseo que deriva de mi labor literaria: frente a la creencia general de que la visión poética del mundo es inofensiva, reivindico el arte y la literatura como un método tan lícito como el científico, o más todavía, para afrontar la realidad y comprenderla. Un asunto de máxima importancia en una época donde la influencia del mercado y la omnipresencia de los conocimientos científicos y tecnológicos arrinconan las humanidades en el espacio educativo.

\section{El poeta y el niño}

Al inicio de su obra El principito,el escritor francés distingue la mirada del niño de la del adulto. El protagonista de la historia, que sueña con ser pintor a los seis años, le muestra a los adultos un dibujo. Estos piensan que se trata de un sombrero. Lo que ha intentado dibujar es, sin embargo, una boa digiriendo un elefante. Apenado, realiza un segundo dibujo donde perfila el contorno del paquidermo en el interior de la serpiente con el objetivo de que los adultos comprendan, ya que "siempre necesitan explicaciones" (Exupéry, 2001, 2). Con este episodio, el escritor enfrenta dos comprensiones del mundo. Sobre todo ejemplifica la incapacidad del adulto para entender al niño; aunque el adulto, alguna vez, pudo ver el elefante sin necesidad de pintarlo, siendo niño.

El autor del artículo compagina su labor docente con la escritura literaria. Hasta la fecha ha publicado seis poemarios reconocidos a nivel nacional. El más reciente, titulado Memoria del pájaro (2016), obtuvo el Premio Hiperión y ha sido acogido por la crítica positivamente (ha sido reseñado en suplementos culturales, entre otros, como El Cultural o Babelia). 
Para mostrar esta diferencia entre la comprensión del mundo del niño y del adulto, recurriré a otro ejemplo sencillo. Si le digo un niño de cuatro años que dibuje un cuerpo humano, trazará una circunferencia con líneas en los costados. Si se lo propongo a un adulto alegará no dibujar bien. Esto se debe a que intentará retratar un cuerpo idéntico al cuerpo literal. El cuerpo, por así decir, que podemos encontrar en un manual de medicina. El dibujo fallido del niño es sensorial ${ }^{3}$, no desliga las percepciones subjetivas de lo que intenta plasmar, vive a salvo de la famosa neutralidad que pretende el adulto con su cuerpo objetivo. Por otra parte, si le dijese al niño que en lugar de un cuerpo humano dibuje un sol, el sol tendrá ojos, nariz y boca. Lo personificará. El adulto, por el contrario, querrá calcar su fluorescencia, la multitud de sus rayos, será una estrella de una galaxia, una bola de fuego, sencillamente. Dos soles, entonces, muy diferentes.

El profesor Louis Porter, a propósito del niño y el juego, rescata el fragmento de la conocida obra Juan Cristóbal, de Romain Rolland, donde el narrador habla sobre los juegos de la infancia:

Se halla en casa, sentado en el suelo, con los pies entre las manos. Acaba de decidir que la pequeña alfombra es un barco y el piso de la habitación un río. Creería ahogarse si saliera de la alfombra. Se halla sorprendido y algo contrariado de que los otros no hacen caso de él al pasar por la habitación. Detiene a su madre jalándole de la falda y le dice: esto es agua. Hay que pasar por el puente. El puente es una hilera de ladrillos rojos. Su madre continúa sin hacerle caso (Porter, 1997, 4).

Pasando por alto las teorías sobre el juego simbólico ${ }^{4}$, lo que nos interesa es que el niño, en éste y en los ejemplos anteriores, se parece al poeta, al hombre creativo. Es decir, que ambos perciben el mundo como un conjunto de relaciones simbólicas. Los dos realizan la misma osadía: ver más cosas en las cosas. La realidad, para ellos, está preñada de significados. Cualquier elemento tiene alma, dice más de lo que parece, es una señal. Acerca de esta afinidad entre el poeta y el niño, el director de cine ruso A. Tarkovsky, en su genial obra Esculpir en el tiempo, afirma lo siguiente: "El poeta es una persona con la fuerza imaginativa y la psicología de un niño. Su impresión del mundo es inmediata, por mucho que se mueva por las grandes ideas del universo. Es decir, no describe el mundo, el mundo es suyo" (Tarkovsky, 2002, 63). Es la misma creencia de Chukovsky cuando, hablando de la riqueza expresiva de la edad infantil, considera al niño como un pequeño poeta afirmando que todos los niños, entre los dos y los seis años, son genios de la lengua. De modo que la diferencia entre el niño y el adulto se percibe no solo en el dibujo, sino también en el plano lingüístico. Esta premisa, temeraria o romántica para algunos, la encuentro muy acertada a partir de

Son muchos los autores que han abordado el estudio del dibujo infantil. El psicólogo C. Burt, por ejemplo, hizo una clasificación por etapas. En la tercera, llamada simbolismo descriptivo (de 5 a 6 años), se hace evidente el esquema imperfecto en el dibujo del hombre; se presta muy poca atención a las proporciones, en especial en lo que respecta a la cabeza, el cuerpo, los brazos, las piernas y los rasgos faciales. Otros, como Georges-Henri Luquet, llamaron a esta etapa realismo fallido. El dibujo pretende ser realista pero no llega a serlo. De ahí que se diga que los niños falsifican la realidad. Pero ya el título de realismo fallido, como veremos, es una creencia contraria a la que se defiende en este artículo.

4 Entiendo el juego simbólico según la definición más extendida, esto es, el juego donde predominan los símbolos. En el ejemplo de Roman Rollaind la alfombra, un objeto real, se transforma en un barco gracias a la intervención de la fantasía y adquiere, por tanto, un carácter simbólico que el adulto no ve. 
la experiencia con mis propios hijos. Uno de ellos, entre otras genialidades, un día dijo mientras salíamos del túnel: "El cielo se ha despertado". En otra ocasión, viendo cómo mi mujer se pintaba los labios, expresó desconcertado: "Mamá, te has manchado la risa". Y no hace mucho, mientras le untábamos la crema protectora antes de ir al mar, preguntó por qué le poníamos un "traje de crema".

El niño es un fabricante incansable de metáforas que brotan de la extrañeza, una extrañeza parecida a la del artista.

Según Miguel J. Pérez, las metáforas que encontramos en el habla infantil se basan en la similitud aristotélica: la metáfora como la traslación del nombre de una cosa a otra, esto es, que un nombre adquiere un significado translaticio o metafórico que se opone al significado común de otra: "Así, una seta se convierte en un paraguas; la espada con que matan al toro es una aguja; el orificio que los médicos dejan en la escayola con que han cubierto el cuerpo del herido es una ventanita para respirar el ombligo". Pero la semejanza, dice, "No es estrictamente de carácter formal externo y aparente. También la metáfora infantil descubre otros tipos de semejanza más profunda" (Pérez, 1993,165). La metáfora hace algo más que llamar nuestra atención: nos obliga a ver las cosas desde una perspectiva diferente, o dicho de otro modo: nos transporta de la costumbre a lo novedoso. ¿No es esto lo mismo que me ocurrió con la anécdota de mi hijo y el túnel? Cuando dijo que el cielo se ha despertado, relató un hecho cotidiano: que la luz del día epiloga la oscuridad del túnel. Pero al decirlo de esa manera valoré más la claridad después de una sombra más o menos larga. Es lo mismo que hace la literatura: decir lo cotidiano como milagroso, o mejor: ver lo milagroso en lo que se ha transformado en cotidiano. La profesora Fajardo Uribe, hablando del poder sintético de la metáfora, afirma que "La metáfora no es solo un asunto del lenguaje, sino que es más bien una forma de hacer manifiesta la concepción del mundo [...] Un vehículo que hace posible profundizar en el conocimiento que tenemos del mundo" (Fajardo, 2005, 49). La metáfora, en este sentido, sabe expresar lo que el lenguaje literal balbuce. Establece vínculos entre las cosas para significar algo más profundo, la misma esencia de las cosas miradas. Es el mismo mecanismo cognitivo con que el ser humano, la criatura artista, viene equipado. No es algo artificial, como el cuerpo que dibuja el adulto. La metáfora le viene dada al niño, es un mecanismo innato.

Esta diferenciación del lenguaje infantil con respecto al lenguaje estándar, según algunos estudiosos, nada tiene que ver con lo que hace el artista. Eduardo Martí, por ejemplo, se opone a una función poética en el lenguaje infantil y afirma la ausencia de una verdadera capacidad metafórica: "La función de la metáfora es, en estos casos, denominativa; el lenguaje tiene una función referencial [...] Que la manera de expresarlo sea sumamente original es una consecuencia involuntaria. En estos casos, la intención primordial del niño no es comparativa" (Martí, 1988, 7). El lingüista y psicólogo Steven Pinker, para explicar las osadías gramaticales de los niños, recurre a explicaciones idénticas. Si un niño dice "Juan ha rompido mis cromos" o "Mi profe sostenió los conejitos", lo que hace es seguir la lógica gramatical, de manera que, según Pinker, "Los errores que comenten los niños rara vez son caprichosos. Muchas veces siguen la lógica de la gramática hasta tal punto, que lo chocante no es que cometan tales errores, sino más bien por qué motivo se les califica como tales" (Pinker, 2003, 299). Otros son más tajantes, como V. Moreno: "Cuando se relacionan ambos términos entre sí (infancia y poesía), se dicen muchas tonterías, muchas frases grandilocuentes, pero cuya fundamentación no se basa en algo real, verificable, sino 
en el deseo de que tales cosas sucedan como nos gustaría que sucedieran" (Moreno, 1999, 35). Los que postulan esta teoría de corte evolutiva señalan que en los niños no existe una intencionalidad poética, puesto que no son conscientes de hacerlo, como en el caso de un poeta, y por tanto "no pueden ser considerados en este sentido artistas" (Ceballos, 2016, 123). La función es puramente referencial, nominativa. "Sin embargo - cito la misma fuente - esto no supone un menoscabo para que cada una de estas creaciones surgidas espontáneamente a diario sea, de hecho, poética" (2016, 123). Y en esto estamos de acuerdo.

Lo que intento argumentar al recurrir a la metáfora es que al niño no le violenta la literatura, como en el caso del adulto, precisamente porque emplea sus mismos procedimientos. Su lenguaje, sea o no deliberadamente poético, es similar al llamado lenguaje literario. El lenguaje, para el niño, es sólo un instrumento más con el que juega mientras aprehende la realidad. Si bien no es intencionadamente poético, el niño, igual que el poeta, discierne el valor simbólico de la realidad que le circunda y que él traslada a sus propios intereses y experiencias; por ejemplo a través de metáforas no premeditadas que elabora para designar con su léxico objetos y seres: a la luna le llama botón. No creo que sea por falta de léxico que el niño haga ese uso chocante del lenguaje. O no solo por eso. Hay una clara similitud entre el poeta y el niño, su empleo del lenguaje es parecido. Se dice que el poeta es más niño que cualquier otro adulto porque conserva los ojos del niño. El niño ve las cosas como un regalo recién abierto bajo el árbol navideño, todo limpio, sin el polvo de la costumbre. Tiene la mirada del turista que rescata un lugar acostumbrado viendo su novedad, su esencia, el lugar tal y como es, antes de la deformación del hastío. Borges afirmó que "La poesía no pretende cambiar por magia un puñado de monedas lógicas. Más bien devuelve el lenguaje a su fuente originaria" (Borges, 2010, 100). Y más adelante: "En la lengua tenemos el hecho de que las palabras son, originariamente, mágicas. Hubo quizá un momento en el que la palabra luz parecía resplandecer y la palabra noche era oscura" (2010, 101). Esto es, precisamente, lo que hace el niño: devolver las palabras, mediante un uso poético, aunque no intencionado, a su verdadero origen.

Se sabe: son muchos los artistas que han relacionado su mirada con la del niño. Goethe afirma, por ejemplo, que la poesía es un estado de infancia conservada. Bécquer, en sus cartas, que solo es poeta aquél capaz de conservar vivos los recuerdos que ha sentido de niño. "Y es que el poeta, como el niño, conserva intacta la capacidad del asombro; conserva viva la imaginación creadora; conserva la visión limpia de los hechos diarios" (Enciso, 2012, 93). Las palabras de Rodari en relación con el binomio-fantástico explican muy bien las construcciones verbales del niño y del artista. Independientemente de la diferente intencionalidad, siguen el mismo procedimiento: sacar las palabras de su contexto. En definitiva, el niño, al igual que el poeta, toma las palabras "liberadas de las cadenas verbales de que forman parte habitualmente. Las palabras son extrañadas, dislocadas, lanzadas una contra otra en un cielo que no habían visto antes" (Rodari, 2010, 17). Irazoki, hablando de la literatura, sostiene que "La poesía no es una delicadeza decorativa, sino una intensidad de la mirada que despierta a la conciencia" (Irazoki, 2016, 11). Y esta mirada aguzada, más intensa, es semejante a la del niño, que mira todo por vez primera. Ambas brotan del descubrimiento.

Ahora bien, es cierto que a partir de los seis o siete años el genio empieza a desaparecer. Es en esta etapa donde el niño, camino del adolescente, aborrecerá definitivamente la literatura o la abrazará como a un juguete con el que aprehenderá la realidad. ¿Qué factores influyen para que se decante por una u otra opción? 


\section{La ruptura}

La desbordante creatividad del niño va diluyéndose a medida que se hace adulto. Esta pérdida, como señalan las estadísticas, va ligada a un abandono paulatino de la literatura. Si bien es inevitable el correr de la edad biológica, también es cierto que hacerse adulto no tiene por qué significar un abandono del texto literario como fuente de placer y descubrimiento. Creo que hay elementos exógenos que conducen a su rechazo y que aceleran la inclusión del alumno en la mentalidad del beneficio o lo inmediato. Estos factores son, entre otros, el propio adulto, que va "corrigiendo" la imaginación del niño y su particular forma de encarar la realidad; el sistema educativo y por supuesto la poderosa influencia del entorno economizado y tecnológico en el que tanto el niño como el adulto viven inmersos.

Cuando me refiero a la influencia negativa del adulto quiero decir que éste enmienda lo que entiende como fallos del niño - las osadías lingüísticas a las que me he referido o los chocantes juegos de su fantasía, por ejemplo- porque los considera inservibles o poco prácticos de cara al futuro profesionalizado al que habrá de enfrentarse para medrar. Los adultos - recordemos el primer capítulo de El principito - aparecen enfrentados a la comprensión propia del niño desde el inicio, propiciando la ruptura. Cuando un niño juega al náufrago, el adulto le dirá que su isla es una mesa. Si mira embobado la ventana, embelesado con las formas que adoptan las nubes, el maestro le espetará diciéndole que sus ojos deben estar fijos en la pizarra, no pensar en las musarañas, dejar esos dibujos que realiza en los márgenes del libro, habrase visto. El adulto es, pues, el encargado de conducirlo a un mundo más literal, menos fantasioso. Y el centro escolar, por desgracia, así como el ambiente en que vive inmerso, son fuerzas que contaminan la visión del niño, que es la primera del ser humano, y que sólo el hombre creativo cultiva en todas las edades. Volviendo a El principito, tras su fracaso como pintor, el protagonista dirá lo siguiente: "Así fue como, a la edad de seis años, abandoné una magnífica carrera de pintor. Estaba desalentado por el fracaso de mi dibujo número $1 \mathrm{y}$ de mi dibujo número 2 . Las personas grandes nunca comprenden nada por sí solas, y es agotador para los niños tener que darles siempre explicaciones" (Exupéry, 2011,2).

No se trata de postular la infancia como una edad idílica, a salvo del mundo y la influencia de los adultos. Quiero decir que es importante potenciar las cualidades propias del niño, incentivarlas, ser conscientes de su poder creativo durante los años escolares. Relacionadas con la ruptura, son poderosamente interesantes las palabras de Martí $(1988,7)$ :

Es extraño que la capacidad metafórica, aparentemente tan arraigada en los pequeños, desaparezca en los inicios de la edad escolar. ¿Será la escuela la responsable de esta evolución, si consideramos su tendencia a la uniformación y al cumplimiento de normas rígidas, elementos que irían en contra de la tendencia creativa y lúdica de los pequeños?

Insisto: sabemos que al niño, durante los primeros años de vida, no le violenta la literatura. Manipular el libro, morderlo, escuchar los diálogos entre dos marionetas, son actividades con las que disfruta. Él mismo, la manera que tiene de emplear el lenguaje, su dibujo o el juego simbólico, es parecido al hombre que se sienta al escritorio para idear una ficción, hace un uso del lenguaje similar, como he dicho. 
Y sabemos también, que, por desgracia, cuando comienza Primaria, la literatura es abordada de manera radicalmente distinta. El libro deja de ser fascinante y se convierte en una tarea difícil, un objeto muerto que hay que autopsiar. Lo que está claro es que es de crucial importancia el modo en que los docentes, en las etapas de Primaria y Secundaria, abordan la enseñanza de la literatura. Juan Mata, que ha escrito largo y tendido sobre el asunto, afirma que "se sabe que gran parte de los éxitos o reveses en la lectura y escritura se dilucidan en los seis o siete años de vida" (Mata, 2008, 212). Ahora bien, ¿cómo se aborda en la actualidad la enseñanza de la lengua en esas edades, una vez el niño empieza Primaria?

En muchas aulas se trabaja [...] con la arcaica concepción de un niño pasivo, ignorante, inmaduro, al que hay que estimular para que se interese por los mecanismos de la escritura y al que hay que conducir cautelosamente hacia el alfabeto mediante ejercicios sencillos y escalonados que, por lo general, carecen de significado y son ajenos a las prácticas sociales $(2008,216)$.

Esto en lo que se refiere al plano de la enseñanza de la lengua. Si observamos lo que sucede con la enseñanza de la literaria, el panorama no es menos desolador:

Ni los profesores leen como se supone que deberían de hacerlo, ni los textos aparecen ante los jóvenes con la vitalidad y la incitación necesarias. La literatura, que apenas tiene ya relevancia en los programas escolares, sigue siendo para muchos alumnos una tediosa sucesión de fechas, nombres propios, títulos y datos sin significado alguno ni conexión con sus vidas $(2008,218)$.

Estoy de acuerdo cuando se afirma que en muchos casos la escuela, convertida en una estructura impositiva, transforma la lectura en un "ejercicio de poder" $(2008,2)$. Me refiero a la obligatoriedad. Según mi propia experiencia, la lectura impuesta acaba conduciendo al rechazo. Hasta que yo no viví una verdadera experiencia lectora, que siempre parte de una iniciativa propia y es un encuentro personal, los libros me parecieron insufribles. En este sentido, es absurdo imponer la lectura de El Lazarillo de Tormes o El Quijote en edades tempranas. O como dice Bartolomé Delgado: "Resultaría improcedente que encargásemos leer El Quijote o La Celestina en la Secundaria obligatoria, por ejemplo. Su complejidad de pensamientos, estilo, etcétera, los hace inadecuados para las edades de estos cursos" (Delgado, 2007, 43). Estos libros, que debieran degustarse en una edad adulta, son percibidos por el niño como un jeroglífico y provocan la asociación de la literatura con el tedio. ¿Cómo obligarle a desentrañar experiencias que solo puede comprender una edad tardía? Las prácticas obligadas acaban produciendo aburrimiento, y además "niegan la alteridad" (Mata, 2008, 2). El texto literario, que debiera ser un descubrimiento emocionante, se convierte en un instrumento de poder, una obligación fastidiosa.

Mientras que en el terreno teórico se ha producido un cambio de mentalidad pienso en los postulados de la llamada Didáctica de la Lengua y la Literatura-, en la práctica sigue habiendo muchas deficiencias a la hora de encarar el fenómeno literario. En la enseñanza de la literatura, dice Bernardelli, "La literatura se presenta como algo alienado y alienante, algo de lo que, por desgracia, se obtendrán resultados deprimentes y limitados" (Bernardelli, 2016, 35). Sobre todo, sigue habiendo maestros no lectores que se ven obligados a participar en las llamadas tareas de animación a 
la lectura porque es conveniente hacerlo o porque obedecen las directrices de una instancia superior, cuando en privado no leen más que lo que les exige su trabajo (en ocasiones, también, abrumados por la ingente burocracia).

A la deficiente situación educativa se añade la influencia de las nuevas y omnipresentes tecnologías. Los niños, actualmente, viven rodeados por la tecnología desde su nacimiento. Cada vez más temprano, adquieren su propio teléfono móvil, que en realidad es un ordenador de bolsillo. ¿Influye esto en la merma de lectores o en la percepción de la literatura como algo secundario, una actividad relegada al ocio, no tan importante como la empresa? Es un tópico afirmar que la lectura morirá por la irrupción de las nuevas tecnologías de la información; pero, si bien es cierto que su irrupción no tiene por qué acabar con los lectores — pensemos que en el debate sobre el libro electrónico y el libro de papel, los que aventuraban la desaparición del segundo han errado-, observo en mis alumnos una pérdida de habilidades, sobre todo una dispersión claramente originada por sus continuas incursiones en las redes sociales. Rara vez logran concentrarse en una misma ocupación más de cinco minutos. Miran constantemente sus móviles aunque no haya nada importante que mirar, como si el solo hecho de saber que lo tienen cerca les sosegara. Es más: muchas de mis "amistades" en Facebook pasan horas incontables dentro de la virtualidad, a veces en busca de afectos que no consiguen fuera de la pantalla, de manera que se va conformando un mundo paralelo y artificial donde se sienten más cómodos, retocando la realidad como demiurgos, a su arbitrio. Yo mismo, por qué no decirlo, he llegado a sentir su poder adictivo. Y al mismo tiempo, desde que uso redes sociales me es más costoso leer concentrado, escribir de manera continuada. Internet facilita la visión de la realidad como el estante de un supermercado: cojo lo que me gusta y lo que no lo deshecho; y siempre del modo más rápido, sin sufrimiento. Es decir, se pasa del silencio y la quietud inherentes a la lectura a lo inmediato y eficaz. Al reino de la instantaneidad. La experiencia lectora, por tanto, se modifica. Ya no leo para enriquecerme, con calma, en mi habitación. Consumo información, que es muy distinto. En el menor tiempo posible, sin contrastarla, creyendo a pies juntillas lo que me ofrece la pantalla que me "obedece". En una reciente entrevista, el pensador Zygmunt Bauman afirmaba que en las redes sociales uno puede añadir amigos y puede borrarlos, y esta tarea se vuelve tan fácil que uno pierde habilidades sociales. No es una postura catastrofista. Lo que intento decir es que este contexto influye en gran medida, o facilita, el abandono de actividades como la lectura de los textos literarios, que requiere recogimiento. "No solamente porque restan tiempo a la lectura, sino también, y principalmente, porque además de inducir a la pereza mental, pueden llegar a provocar en el ser humano una alteración de valores y estilos de vida que transforme los modos de asimilar la información" (Delgado, 2007, 39). Si bien se admiten sus ventajas, los niños requieren una educación en la era de la sobre información. Deben aprender a filtrar, seleccionar cuanto llega a su mirada.

El docente, entonces, no debe menospreciar estos medios con que convive el alumno. Debe tener claro el caldo en el que vivimos, influenciado por la visión mercantilista. La influencia del Homo oeconomicus es algo incuestionable en este mundo en el que, según Ordine, "Un martillo vale más que una sinfonía, un cuchillo más que una poesía, una llave inglesa más que un cuadro: porque es fácil hacerse cargo de la eficacia de un utensilio mientras que resulta cada vez más difícil entender para qué pueden servir la música, la literatura o el arte" (Ordine, 2016, 12). 


\section{Invertir la situación: por una didáctica de la extrañeza}

Según la profesora Morote, hay dos caminos en la enseñanza de la literatura. En el primero, el alumno acaba asociándola con "obligatoriedad, imposición, monotonía, aburrimiento, memorismo, incomprensión"; en el segundo, con "disfrute, encuentro, misterio, fascinación, exploración, emoción, divertimento, juego, curiosidad, crítica, comprensión, entendimiento, apertura..." (Morote, 1999, 317). Rodari piensa lo mismo al expresar que "Hay dos tipos de niño lector, el que lee para la escuela porque es su tarea y el que lee para sí mismo, para satisfacer su necesidad de información o para alimentar la imaginación, para jugar a" (Rodari, 1977, 28). Mis alumnos, la mayoría, transitan el primer camino. Es curioso que en el primer día de clase, al proponer una lluvia de ideas a partir de la palabra literatura, me respondan con nombres abstractos como autores, libros, cuentos o figuras retóricas. Esta definición de literatura demuestra que, durante la etapa escolar, han asimilado la literatura como un compendio de fechas, autores y textos analizables; nada que ver con el disfrute o la fascinación, palabras del segundo camino. Éste, sin duda, puede ejemplificarse con la experiencia de los escritores, que antes de escribir han sido buenos lectores y que recuerdan con emoción los primeros libros que engulleron. Proust dirá: “Tal vez no haya días más plenamente vividos en nuestra infancia que aquellos que creímos dejar pasar sin vivirlos, aquellos que pasamos con uno de nuestros libros preferidos" (Proust, 2012, 59). Sartre, en Las palabras, evoca los sentimientos que albergaba frente a la biblioteca familiar: "Los libros fueron mis pájaros y mis nidos, mis animales domésticos, mi establo y mi campo; la biblioteca era el mundo atrapado en un espejo; tenía el espesor infinito, la variedad, la imprevisibilidad" (Sartre, 2002, 41) O también: "Encontré el universo en los libros: asimilado, etiquetado, pensado, aún temible" $(2002,43)$.

Está claro que el origen de un buen lector tiene lugar en el ámbito familiar. Pero el centro escolar, que debe suplir las carencias familiares e incentivar el acercamiento del niño a la lectura, no afronta el problema como debiera.

Volviendo a Mata:

La paradoja es que, mientras desde ámbitos tan diversos como la filosofía, la psicología o las neurociencias se reivindica el papel revelador y libertador de la literatura, en las aulas escasean las discusiones libres, se asfixia por improcedente la expresión de las emociones y se ignoran sus posibilidades éticas. En vez de contribuir a la transformación de los alumnos en lectores, las obras literarias sirven como simple materia para su evaluación como estudiantes (Mata, 2008, 218).

Sabiendo que existe un periodo crítico que comprende los primeros años escolares y que los alumnos a esas edades son seducidos por otros placeres más inmediatos, propios del mundo de la instantaneidad, la pregunta que podemos hacernos es la siguiente: ¿cómo conseguir, en la medida de lo posible, que la literatura sea divertimento y no obligatoriedad o imposición? Esta pregunta, en realidad, debiera ir precedida por otra que Mata considera esencial: “¿Para qué leer, por qué insistir tanto en su necesidad y su práctica?" (Mata, 2008, 211)

A continuación expondré algunos de los frutos que ha producido en mi persona la asidua lectura de textos literarios y que son los que expongo cuando en calidad de poeta me invitan a las escuelas para charlar con los padres. 
En primer lugar, la lectura exige silencio, quedarnos quietos. El problema número uno de nuestra sociedad es el ruido. Y también la prisa. Durante la jornada, nos olvidamos de algo tan sencillo como sentarnos, callarnos y recoger la atención. Continuamente estamos dispersos, preocupados por miles de cosas que si lo pensamos bien son inútiles. Por ello, la lectura ayuda al niño a concentrarse, a familiarizarse con la quietud y el silencio en una época donde la identidad está fragmentada y es necesario que el hombre no huya de sí mismo, se amigue con el silencio y sus preguntas.

La lectura, además, permite la alteridad. Lejos de ser una actividad autista, es un diálogo, y aún más: nos pone en la piel del otro. Estamos en una sociedad profundamente egocéntrica donde ya empezamos a ver las consecuencias en las nuevas generaciones. La vida, sin embargo, es un aprendizaje del tú, el descubrimiento de los demás con todas sus diferencias. Y esto lo consigue la lectura, porque leyendo nos metemos en otras pieles, sentimos las emociones de los personajes en situaciones en las que nunca hemos estado, vemos la realidad como en un caleidoscopio, con infinitos matices, renunciando a nuestros propios esquemas o modificándolos a partir de la experiencia lectora. El niño, leyendo lo que le ocurre a los hermanos Hänsel y Gratel siente la amenaza, el peligro, la necesidad. En las novelas hay una pluralidad de voces y cada una con su punto de vista. La literatura aborda al hombre en toda su complejidad. Y en edades tan egocéntricas como la infancia y la adolescencia la lectura de ficciones puede ser un camino óptimo para conseguir la empatía y salir de los propios intereses, ver la amplitud del mundo en que vivimos, su variedad de personas.

En tercer lugar, la lectura nos ayuda a pensarnos y a pensar la realidad, el mundo que nos rodea. Conocer al ser humano y sus pasiones: al albergar complejidad de voces, unos sufren, otros se alegran. La literatura, a fin de cuentas, es un mosaico del que si uno se aleja comprende al ser humano, y cómo éste reacciona ante el sufrimiento, conoce la muerte, el dolor, pero también la alegría o el amor más auténtico. Mientras Madame Bovary o Ana Karenina nos ofrecen distintos puntos de vista sobre la psicología de la mujer que adultera, Crimen y castigo se adentra en las catacumbas de la conciencia de quien ha cometido un asesinato, y Jack London, con su preciosa obra La llamada de lo salvaje, nos habla de la crueldad de algunos hombres y la nobleza de los animales.

Podría citar más propiedades de la lectura, pero basten las aquí expuestas. Después de responder sucintamente al planteamiento del profesor Juan Mata, creo que lo primero que debe asimilar un alumno es que la lectura no es algo tedioso, sino todo lo contrario. La lectura debiera estar ligada a una experiencia seductora, gozosa. Es urgente acabar con las prácticas escolares que dinamitan el disfrute y la convierten en algo engorroso. Es necesario, en primer lugar, algo tan elemental como que el docente sea un buen lector, haya tenido previamente una experiencia lectora, los libros hayan producido en él un eco imborrable, único. Afirma Lázaro Carreter que "El profesor de literatura tiene que ser un profesor de entusiasmo" (Morote, 1999, 314-315). Su entusiasmo contagiaría a los alumnos y no contribuiría a una cadena de errores que se perpetúa hasta la universidad. De lo contrario, el profesor es un comercial que nunca ha creído en el producto que intenta vender con entusiasmo impostado. Lectura y curiosidad, además, deben ir de la mano. La misma curiosidad de la que hablamos antes y que emparenta al niño con el poeta. Debe existir, por tanto, una continuidad entre la etapa infantil, irreprochable, y las siguientes. El 
texto literario no debe convertirse en un objeto parecido a los cadáveres con que practican los residentes de Medicina. A este respecto, las palabras de Bernardinelli son elocuentes: "El primer error que, sin ni siquiera darnos cuenta, aprendemos [...] es que las obras literarias fueron escritas por autores y están ahí ante nosotros con el fin de ser enseñadas y estudiadas" (Bernardinelli, 2016, 35). Siguiendo con el crítico literario, "aquellos que enseñan y estudian literatura [...] tienden a olvidar que las obras literarias no fueron escritas por sus autores para ser enseñadas y estudiadas, sino para ser leídas y releídas $(2016,36)$. Porque, una vez finalizada la etapa infantil, el libro pasa a ser un objeto y no compañero de juego que permite conocer el mundo. El libro, hasta entonces un objeto físico que se podía manipular, morder, palpar, pasa a ser un conjunto de símbolos memorizables y textos aburridos sobre los que el profesor hace preguntas. Este punto de inflexión se debe, entre otras cosas, a la falsa creencia de que hay menos seriedad en el juego que en otro tipo de actividades como el análisis textual. Sostengo, por el contrario, que debería potenciarse una didáctica de los ojos, esto es, fomentar la continuidad con la etapa infantil, donde el libro y el juego no están reñidos, teniendo en cuenta la extrañeza del niño, que es la misma que la del artista, esa extrañeza de la que brota en su mayor parte la literatura. Que el libro, terminada la etapa infantil, siga siendo motivo de regocijo. La literatura abordada lúdicamente, desde el goce. Rodari, a este respecto, plantea la necesidad del libro como juego:

Definir el libro como un juguete no significa en absoluto faltarle el respeto, sino sacarlo de la biblioteca para lanzarlo en medio de la vida, para que sea un instrumento de vida [...] Para una literatura infantil que no caiga sobre los niños como un peso externo o como una tarea aburrida, sino que salga de ellos, viva con ellos, para ayudarlos a crecer y a vivir más arriba, tendríamos que conseguir relacionar íntimamente estos tres sustantivos: imaginación-juego-libro (Rodari, 1977, 30).

Para que esto ocurra, es indispensable que se acabe con la obligatoriedad: las lecturas obligatorias debieran estar prohibidas. Yo mismo, durante el curso pasado, realicé un sencillo cambio didáctico tras muchas otras tentativas. Hasta mi llegada, los alumnos estaban obligados a leer tres novelas durante el semestre que duraba la asignatura. Los resultados, año tras año, eran catastróficos. La mayoría realizaba un batiburrillo de sinopsis encontradas en la Web que me recitaban como autómatas, sin el menor interés por la lectura de la que hablaban. Consciente de que aquél no era el camino, propuse que cada uno comprase un libro, me daba igual si era o no literatura. El único requisito era el siguiente: que cada alumno, en el momento de entrevistarse conmigo, trajese el libro subrayado y el ticket de la compra. La necesidad de que lo comprasen durante el tiempo de la asignatura era sencilla: pensé que si ellos elegían el tema del libro, les costaría menos comprarlo que si la lectura era impuesta. El resultado fue totalmente satisfactorio. Los alumnos disfrutaron leyendo. La experiencia lectora se había logrado. Venían al despacho felices, con ganas de contarme el eco que su libro había producido en ellos, y no para bombardearme con sinopsis y datos sacados de Wikipedia o El rincón del vago.

De esto se deduce otro factor indispensable: no desligar la práctica de la teoría. Quiero decir que, en lugar de enseñar las figuras literarias como una ristra de nombres complejos, ayudarles a potenciar la mirada curiosa del poeta para que las figuras broten de manera espontánea, y luego ya habrá tiempo de ponerles nombre. 
No versificar muy bien ni saber que un verso de once sílabas se llama endecasílabo, sino que asocien la escritura con su propia vida, haciendo un diario y una puesta en común, donde también puedan dibujar, romper las páginas, mostrar su enfado. Partiendo de esta premisa, las propuestas didácticas se multiplican. Es reconfortante cuando, tras mandarles comprar un cuaderno con páginas en blanco, vienen cada semana para poner en común sus reflexiones, sentimientos, y ver cómo disfrutan asociando el proceso escritor al encuentro con uno mismo, esto es: la escritura literaria como herramienta que explora la propia cotidianeidad, no ya como la propiedad de unos tipos aislados que escriben cosas difíciles y abstractas. En definitiva, se trata de invertir la didáctica: en lugar de lecturas obligatorias, lecturas voluntarias que tengan que ver con el interés particular de cada alumno; en lugar de reglas ortográficas o nombres de versos y figuras literarias, actividades creativas donde el alumno ejercite su curiosidad, la extrañeza, pueda experimentar el proceso escritor como algo emocionante, pasar de la monotonía al descubrimiento.

\section{Conclusiones}

Al niño le gusta la literatura: se divierte, por ejemplo, en un espectáculo de guiñoles, con la rima de los poemas, manipulando libros o escuchando cuentos orales. Es más: emplea el lenguaje de un modo parecido al del poeta, aunque dicho empleo sea involuntario. Lo importante es que concibe el mundo simbólicamente, y extraña o disloca las palabras creando el asombro del adulto, que no comprende. Su empleo de la lengua es creativo. Ahora bien, está más que demostrado que la mayoría de los alumnos, durante las etapas de Primaria y Secundaria, pasan a ver la literatura como algo tedioso a la par que abandonan la desbordante creatividad infantil, o más que abandonarla, la dirigen hacia otros intereses más prácticos o útiles.

Esta ruptura, en parte, se produce por la influencia del ámbito familiar, pero es determinante la actuación docente del centro educativo, que en la mayoría de los casos aborda el texto literario desligándolo del placer. Esto, sumado a un factor ambiental donde prevalece lo inmediato, relega actividades como la lectura y la escritura a un segundo plano (actividades sencillas que requieren recogimiento, sentarse con uno mismo). Hace falta una didáctica que robustezca la curiosidad propia del niño, que es la fuente y el germen de la literatura. Que el libro, concluida la etapa infantil, siga siendo un motivo de regocijo. Que sea vida, y no materia analizable. Hacen falta, sobre todo, docentes que, previamente a la transmisión de conocimientos, hayan tenido una verdadera experiencia lectora y sepan concretar con didácticas atractivas su entusiasmo. De este modo propiciaremos nuevos lectores, futuros hombres y mujeres capaces del silencio y la quietud en esta época ensordecedora.

\section{Bibliografía}

Berardinelli, Alfonso (2016): Leer es un riesgo, Madrid, Círculo de Tiza. Borges, Jorge Luis (2010): Arte poética. Seis conferencias, Barcelona, Crítica. Burt, Cyril Lodowic (1921): Pruebas mentales y académicas, Londres, PS. King and Son. 
Ceballos Viro, Ignacio (2016): Iniciación literaria en Educación Infantil, Logroño (La Rioja), UNIR (Universidad Internacional de la Rioja).

Cervera, Juan (1989): "En torno a la literatura infantil", Cauce, Revista de Filología y su Didáctica, 12, 157-168.

Cervera, Juan (1984): La literatura infantil en la educación básica, Madrid, Cincel.

Colomer, Teresa (1991): "De la enseñanza de la literatura a la educación literaria", Comunicación, Lenguaje y Educación, 9, 21-31.

Delgado, Bartolomé (2007): "Fundamentos del proceso lector. Motivar la lectura en Educación Secundaria", Ocnos, 3, 39-53.

Enciso, Julia (2012): Sobre el hombro herido del mundo. Voces de la mirada, Madrid, Visión Libros.

Fajardo Uribe, Luz Amparo (2006): "La metáfora como proceso cognitivo", Función y Forma, 19, 47-56.

Femenías, Ma Luisa (1996): “Conocimiento y metáfora en Aristóteles”, Revista de Filosofía y Teoría Política, La Plata, 31-32, 152-16.

Irazoki Fernández, Mikel (2016): Orquesta de desaparecidos, Madrid,Hiperión.

García Montero, Luis (2000): Lecciones de poesía para niños inquietos, Granada,Comares.

Luquet, Georges-Henri (1978): El dibujo infantil, Barcelona, Médica y Técnica.

Martí, Eduardo (1988): "Primeras creaciones en el lenguaje infantil. El caso de las metáforas", Infancia y Aprendizaje, 43, 3-12.

Mata, Juan (2008): "Leer cómo, enseñar qué: las formaciones en la lectura", en La lectura En España. Informe 2008: leer para aprender. Fundación Germán Sánchez Ruipérez y Federación de Gremios de Editores de España. Disponible [en línea] en: http://www. lalectura.es/2008/

Moreno, Víctor (1999): “Textos poéticos en la Educación Secundaria. Textos de Didáctica de la Lengua y la Literatura, 21, Barcelona, 35-47.

Morote, Pascuala (1999): “Creatividad y motivación en la enseñanza de la literatura" [en línea], Actas del XXXIII Congreso Internacional de la Asociación Europea de Profesores de Español, 311-336: https://dialnet.unirioja.es/servlet/articulo?codigo=4829388

Ordine, Nuccio (2013): La utilidad de lo inútil, Barcelona,Acantilado.

Pérez, José Miguel (1993): "La metáfora en el habla infantil. Sencillez y expresividad", Didáctica, 5, Complutense, 165-186.

Pinker, Steven (1994): El instinto del lenguaje, Madrid, Alianza Editorial.

Porter, Louis(1997): "Los niños y la poesía” [en línea], UAM-Xochimilco. Disponible en: https://enriquecordero.files.wordpress.com/2010/10/los-nic3b1os-y-la-poesia_luis-porter_uam_19971.pdf

Proust, Marcel (2012): Días de lectura, Barcelona, Santillana.

Rodari, Gianni (2010): Gramática de la fantasía, Barcelona, Planeta.

Rodari, Gianni (1987): "La imaginación en la literatura infantil”" [en línea], Piedra Libre, 2. Disponible en: http://www.imaginaria.com.ar/12/5/rodari2.htm

Rodari, Gianni (1977): “Un juguete llamado libro”, Cuadernos de Pedagogía, 36, 28-31.

Saint-Exupéry, Antoine (2001): El principito, Barcelona, Salamandra.

Sartre, Jean-Paul (2002): Las palabras, Buenos Aires, Losada.

Tarkovsky, Andrei (2002): Esculpir en el tiempo, Madrid, Rialp.

Tejerina Lobo, Isabel (2005): "Literatura infantil y formación de un nuevo maestro" [en línea], Biblioteca Virtual Miguel de Cervantes, Alicante. Disponible en: http://www. cervantesvirtual.com/obra-visor/literatura-infantil-y-formacin-de-un-nuevo-maestro-0/ html/003f3304-82b2-11df-acc7-002185ce6064_2.html 